\title{
Mesoscale model simulation of low level equatorial winds over Borneo during the haze episode of September 1997
}

\author{
Mastura Mahmud \\ Earth Observation Centre, Faculty of Social Sciences and Humanities, \\ Universiti Kebangsaan Malaysia, Bangi 43600, Selangor, Malaysia. \\ e-mail: mastura@pkrisc.cc.ukm.my
}

The large-scale vegetation fires instigated by the local farmers during the dry period of the major El Niño event in 1997 can be considered as one of the worst environmental disasters that have occurred in southeast Asia in recent history. This study investigated the local meteorology characteristics of an equatorial environment within a domain that includes the northwestern part of Borneo from the 17 to 27 September 1997 during the height of the haze episode by utilizing a limited area three-dimensional meteorological and dispersion model, The Air Pollution Model (TAPM).

Daily land and sea breeze conditions near the northwestern coast of Borneo in the state of Sarawak, Malaysia were predicted with moderate success by the index of agreement of less than one between the observed and simulated values for wind speed and a slight overprediction of 2.3 of the skill indicator that evaluates the standard deviation to the observed values. The innermost domain of study comprises an area of $24,193 \mathrm{~km}^{2}$, from approximately $109^{\circ} \mathrm{E}$ to $111^{\circ} \mathrm{E}$, and from $1^{\circ} \mathrm{N}$ to $2.3^{\circ} \mathrm{N}$, which includes a part of the South China Sea. Tracer analysis of air particles that were sourced in the state of Sarawak on the island of Borneo verified the existence of the landward and shoreward movements of the air during the simulation of the low level wind field. Polluted air particles were transported seawards during night-time, and landwards during daytime, highlighting the recirculation features of aged and newer air particles during the length of eleven days throughout the model simulation. Near calm conditions at low levels were simulated by the trajectory analysis from midnight to mid-day on the 22 of September 1997. Low-level turbulence within the planetary boundary layer in terms of the total kinetic energy was weak, congruent with the weak strength of low level winds that reduced the ability of the air to transport the pollutants.

Statistical evaluation showed that parameters such as the systematic RMSE and unsystematic RMSE between the observed and simulated values indicated the modest skill of the model in simulating the low level winds. Otherwise, the equatorial meteorological parameters such as wind speed and temperature were successfully simulated by the model with comparatively high correlation coefficients, lower RMSEs and moderately high indices of agreement with observed values.

\section{Introduction}

In southeast Asia, fires are still utilized by farmers and plantation companies for land clearing activities during the burning season from June to
September. More than 9.5 million hectares were burned in Indonesia during the major El Niño event of 1997-1998 (Qadri 2001) and approximately $49 \%$ or $4,655,000$ hectares of the forest land was burned in Borneo, Sumatera, Sulawesi, Irian

Keywords. Equatorial region; low-level meteorological parameters; biomass burning; haze; southeast Asia; Sarawak. 


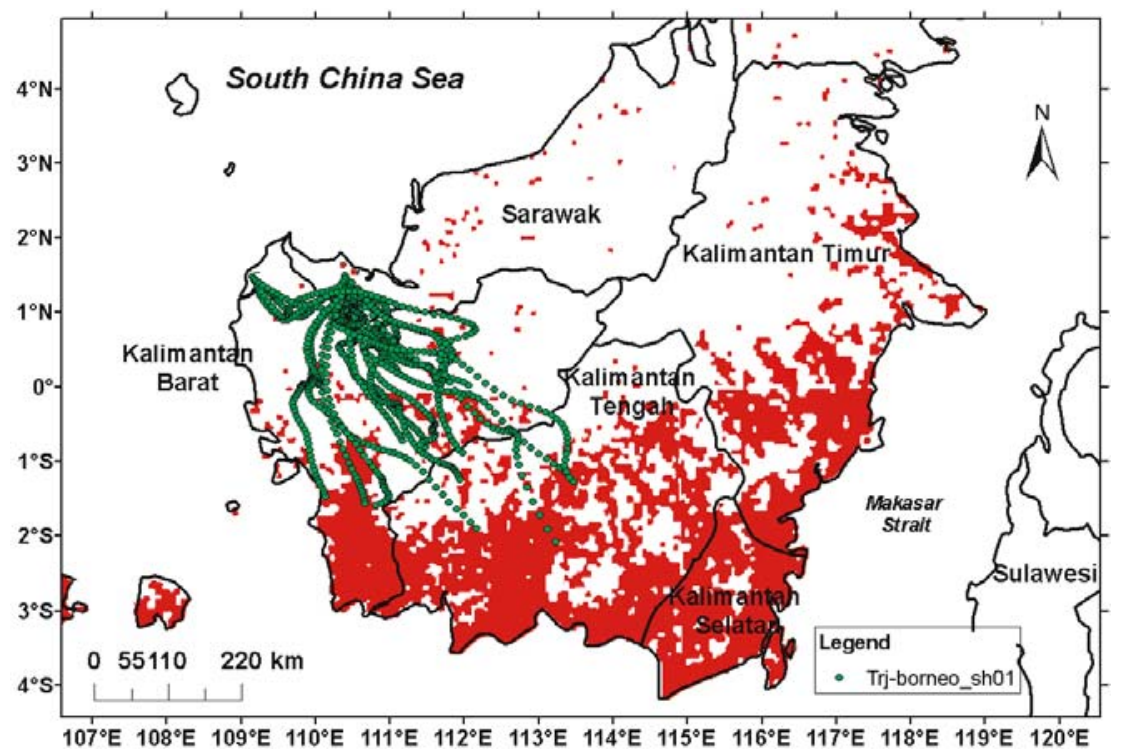

Figure 1. Distribution of accumulated active fire counts obtained from the NOAA AVHRR satellite during September 1997 was sourced from the Forest Fire Prevention Management Project (JICA/PKR). The ensemble of backward trajectories that ended on the 25 of September 1997 showed the slow advection of the air particles from central Borneo towards northern Borneo were all beneath the height of $500 \mathrm{~m}$.

Jaya and Java (Rowell and Moore 2000). Profitable interests were cited as one of the reasons behind the causes of the biogenic fires in Indonesia. Largescale forest exploitation and conversion activities for oil palm and industrial timber plantations in Sumatera and Kalimantan have led to a rapid increase in fire hazard where the patchwork of degraded forest containing dry biomass burn easily (Rowell and Moore 2000).

The major El Niño phenomenon instigated dry conditions over the western rim of the western north Pacific region, of which Borneo is no exception. Evidence for this can be found from the meteorological station at Kuching, located in the state of Sarawak, Malaysia on the northwestern coast of Borneo, where the total average rainfall of $887 \mathrm{~mm}$ from May to October in 1997 were $40 \%$ below the 30-year climatological mean total of $1487 \mathrm{~mm}$. Thus, the above fact establishes the scenario of the local environmental conditions as to why the haze episode from the uncontrolled burning was severe during the dry El Niño period of 1997.

Figure 1 shows the distribution of active fire counts in Borneo in September 1997, derived from the National Oceanic Atmospheric Administration (NOAA) Advanced Very High Resolution Radiometer (AVHRR) satellite. Most of the burned areas were located in the provinces of Kalimantan Tengah, Kalimantan Selatan and Kalimantan Timur on the island of Borneo, Indonesia. For this study, it was estimated that $450,000 \mathrm{~km}^{2}$ of land was burned in Borneo.
Smoke particles from the burning areas in the provinces of Kalimantan Tengah and Kalimantan Barat were transported to the northwestern coast of Borneo at Kuching by the weak prevailing low level winds below the heights of $500 \mathrm{~m}$ as shown by the ensemble backward trajectory analysis (figure 1). The backward trajectories were computed three days prior to the 23 of September, at the height of the haze event, by the Hybrid Single-Particle Lagrangian Integrated Trajectory (HYSPLIT) model (Draxler and Hess 1998). The 27 possible multiple trajectories that ended in Kuching showed the probable starting points that were calculated by offsetting the meteorological data by a fixed grid factor in the horizontal and a 0.01 sigma unit in the vertical (Draxler et al 2008).

Transboundary haze that affected the Kuching station was reflected by reduced visibility and high concentrations of particulate matter sized smaller than 10 microns $\left(\mathrm{PM}_{10}\right)$. The Malaysian Air Pollutant Index (MAPI) attained the 764 level at Kuching on the 23 of September 1997, considered dangerous to the health of the local community (figure 2). The MAPI is based on the United States Environmental Protection Agency (USEPA) pollutant standard index (PSI), which consists of the components of $\mathrm{PM}_{10}$, sulphur dioxide, nitrogen dioxide, carbon monoxide and ozone. An index of 100 and below signifies a safe limit, whereas levels above 100 signifies unhealthy, very unhealthy (201-299) or hazardous (more than 300) classifications. Kuching continued to record MAPI levels that exceeded 200 from the 18 to the 27 


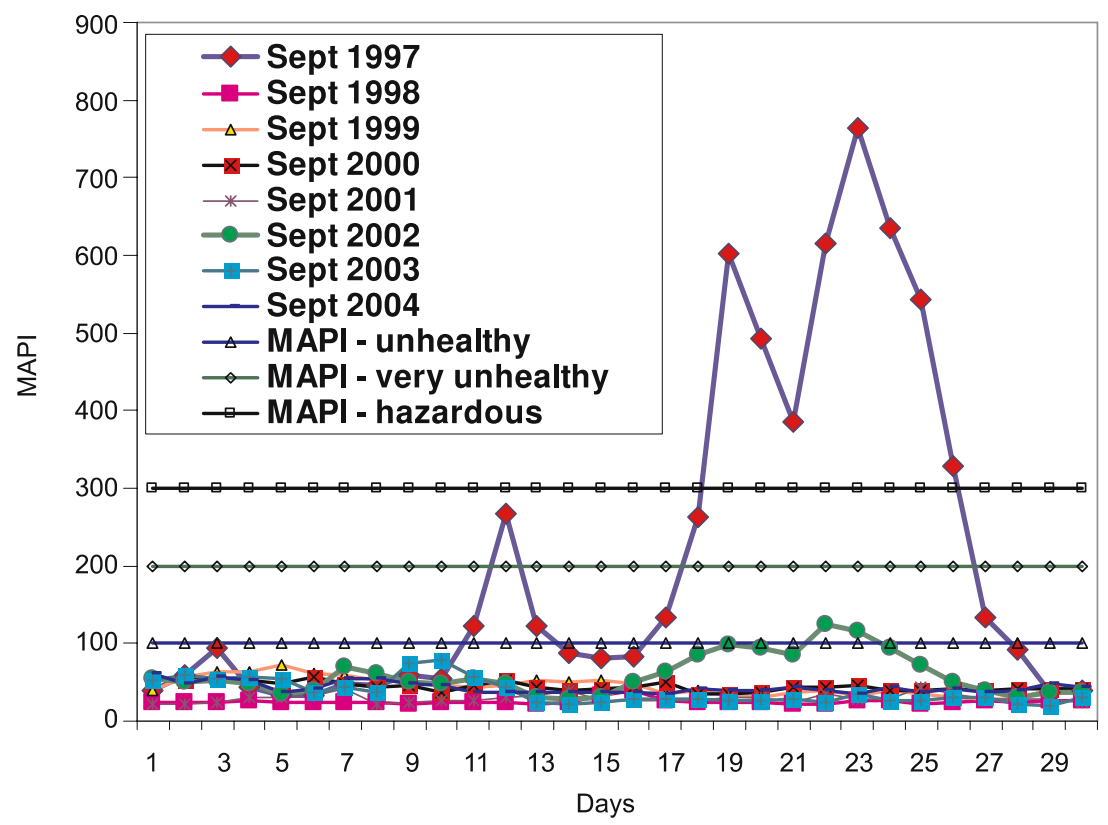

Figure 2. Comparison of the MAPI levels at the Kuching air quality station in the state of Sarawak from September 1997 to 2004 .

of September. Cloud formation is inhibited by the vast amount of suspended particulates that absorb solar radiation and reduced surface evaporation (Kaufman et al 2005) during the dry El Niño episode which is vital to cleanse the air through the processes of rainout, washout or wet deposition. Comparatively, other MAPI values from September 1998 to 2004 represented good air quality levels in contrast to those of September 1997, which illustrate the deterioration of the air quality and severity of the 1997 haze episode in Kuching.

The daily mean air pollutants at Kuching for September 1997 are shown in figure 3(a and b). Mean daily carbon monoxide (CO) concentrations of more than $5 \mathrm{ppm}$, which was beneath the ambient air limit of $10 \mathrm{ppm}$ set by the Recommended Malaysian Air Quality Regulations, occurred from the 18 to 27 of September, concurrent with the elevated MAPI levels during the height of the haze episode (figure 3a). This was the only pollutant that displayed enhanced concentrations besides the elevated $\mathrm{PM}_{10}$ concentrations, during the height of the haze episode, while other parameters such as non-methane hydrocarbon (NmHC), total hydrocarbon (THC), methane $\left(\mathrm{CH}_{4}\right)$ shown in figure $3(\mathrm{a})$, nitrogen oxide (NOx), sulphur dioxide $(\mathrm{SOx})$, ozone $\left(\mathrm{O}_{3}\right)$, nitrous oxide $\left(\mathrm{N}_{2} \mathrm{O}\right)$ and nitrogen oxide (NO) did not increase significantly, particularly from the 18 to 27 of September 1997 (figure 3b). The increase in the trend of the concentrations of $\mathrm{PM}_{10}$ and $\mathrm{CO}$ concentrations were similar, particularly from the 17 until 28 September, with the contribution of the $\mathrm{PM}_{10}$ concentrations that was overwhelmingly larger than the CO component in the MAPI. Carbon monoxide is produced as a by-product from incomplete combustion of carbon. The increase in the $\mathrm{CO}$ concentrations is consistent with the fires and transboundary haze where $\mathrm{CO}$ is one of the sources of chemically reactive gases produced from biomass burning (Levine 1994). Carbon monoxide is used as a tracer for pollution sources in the upper troposphere, which is monitored by the Tropospheric Emission Spectrometer (TES) onboard NASA's Aura satellite (Halland et al 2008).

Transportation modelling based on the outputs of the general circulation models of a $35-\mathrm{km}$ grid horizontal resolution has captured the relatively weak monsoon development of southeast Asia during the 1997 haze episode (Koe et al 2001). Simulation on the transportation of anthropogenic sulphate and sulphur dioxide in southeast Asia that utilized the $50 \mathrm{~km}$ horizontal grid of the Multiple-scale Atmospheric Transport and CHemical modelling system (MATCH) model was investigated by Siniarovinaa and Engardtb (2005). These studies showed that transportation of pollutants had been based on synoptic-scale resolutions. Thus a study that highlights the mesoscale features that influence the transportation of transboundary aerosols from burned biomass within the planetary boundary layer is needed, particularly an investigation of the local wind regime over different surface conditions that include the marine air of the South China Sea and the land surface of northwestern Borneo during that occasion. In this study, a limited area meteorological and air pollution model 


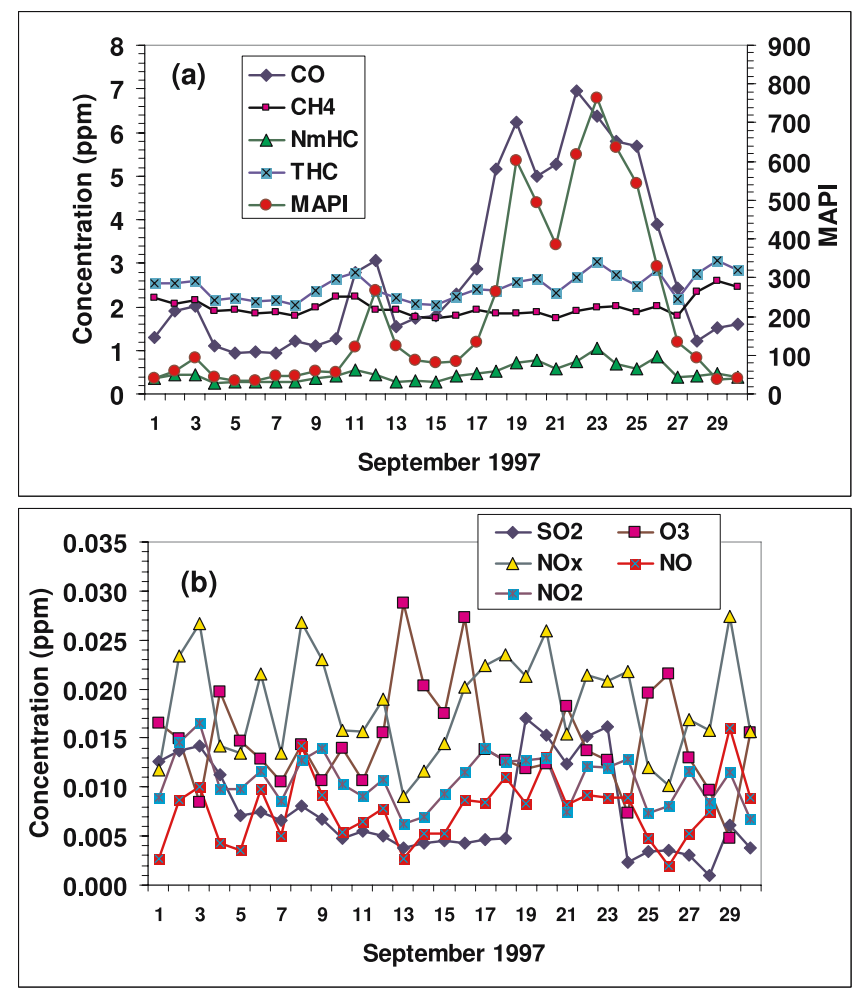

Figure 3. (a) Concentrations of gases such as $\mathrm{CO}, \mathrm{CH}_{4}$, $\mathrm{NmHC}$ and $\mathrm{THC}$, and (b) concentrations of gaseous $\mathrm{SO}_{2}$, NOx, NO, and $\mathrm{O}_{3}$ at Kuching during September 1997.

called The Air Pollution Model (TAPM) is utilized (Hurley et al 2005). One of the advantages of this model is that observed meteorological data can also be integrated in this model. TAPM has simulated meteorological fields for the dispersion prediction of pollutants (Hurley et al 2005) such as turbulence conditions (Hurley 1997), the seabreeze phenomenon (Hurley and Luhar 2000), air pollution of an industrial area (Hurley et al 2001), and simulate urban photochemical smog (Hurley et al 2003).

In the next section, the model configuration of TAPM is discussed briefly, and followed by the results obtained from the simulation of the meteorological wind regime. Meteorological data from the Kuching air quality station was compared to the outputs from TAPM during the poor air quality episode in September 1997. The performance of TAPM in simulating the meteorological field is evaluated through some simple statistical analysis, and ensued by the conclusion.

\section{Methodology and model configuration}

TAPM is a three-dimensional limited area prognostic meteorological and air pollution model. It uses the complete equations governing the behavior of the atmosphere, thermodynamics, moisture conservation, turbulence and dispersion (Hurley et al 2005). One of the basic meteorological variables, the wind velocity is determined for the zonal and meridional components from the momentum equations.

Input parameters to the model include global databases of terrain height, land use, sea-surface temperature, and synoptic meteorological analyses (Hurley et al 2005). TAPM's default database of global terrain height and land cover characterization at a resolution grid of $1 \mathrm{~km}$ is based on data from the US Geological Survey. Further description of the model is given by Hurley et al (2005). The horizontal wind components are solved from momentum equations, while vertical velocity is solved from the incompressible continuity equation that follows the terrain. The maximum wind speed is set at the default value of $30 \mathrm{~m} \mathrm{~s}^{-1}$ so that the Courant numbers are less than one in order to reduce numerical errors, especially near the top of the model and for non-hydrostatic conditions (Hurley et al 2005). Parameters such as potential virtual temperature, specific humidity of water vapour, cloud water and rain water are solved from scalar equations (Luhar and Hurley 2003).

Pressure is generated by the hydrostatic and non-hydrostatic components, which follows the Exner pressure function (Hurley et al 2005). The turbulence closure terms in these mean equations utilize a gradient diffusion approach, which consist of a counter-gradient term for the heat flux, with eddy diffusivity determined using prognostic equations for turbulence kinetic energy and eddy dissipation rate (Luhar and Hurley 2003). The earth's surface is represented by a weighted vegetative canopy, with a choice of 27 vegetation types. The soil parameterization utilizes the force-restore approach for moisture and temperature (Kowalczyk et al 1991), with three options of soil types. The urban land-use scheme includes the force-restore approach for zero moisture and temperature, with an anthropogenic heat flux and only one category for urban (Pielke 1984; Oke 1988). Radiative fluxes at the surface and at upper levels are also incorporated into the model (Hurley et al 2005). Parameterization of cloud microphysics of warm rain includes condensation, evaporation and collection processes (Katzfey and Ryan 1997).

One of the disadvantages of TAPM is the limitation of the maximum horizontal domain extent that cannot exceed $1500 \times 1500 \mathrm{~km}$. This is due to the model equations that neglect the curvature of the earth and assume a uniform distance grid spacing across the domain (Hurley et al 2005). An error message is obtained if the outer grid domain size exceeds $1500 \mathrm{~km}$ in either direction (Hurley et al 2005). Therefore, areas larger 
(a) $30 \mathrm{~km}$ grid

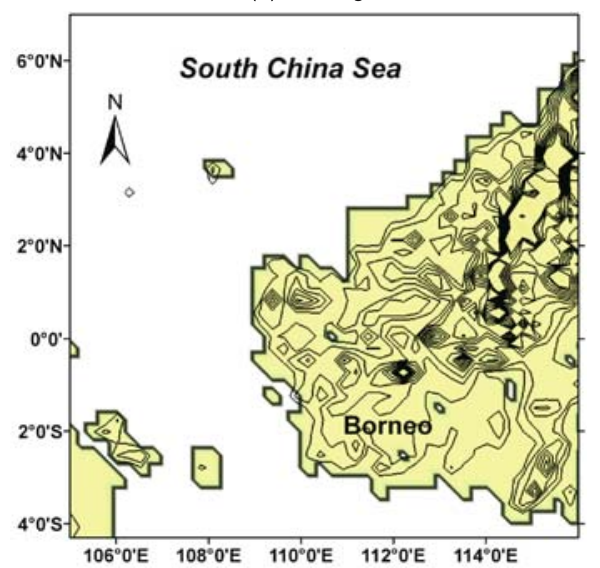

(b) $10 \mathrm{~km}$ grid

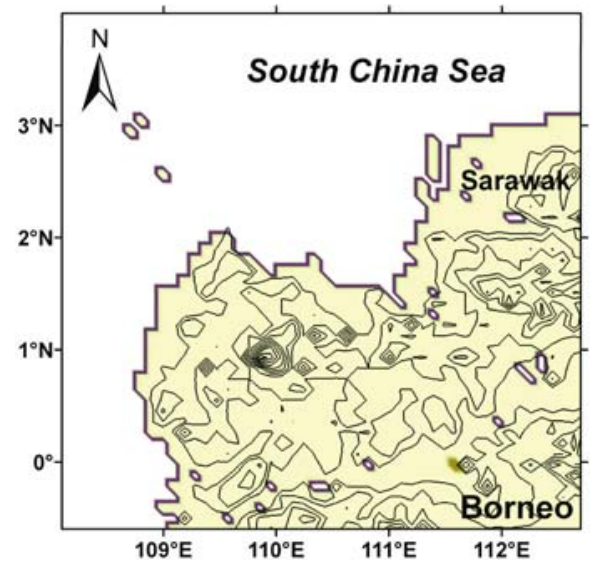

(c) $3 \mathrm{~km}$ grid

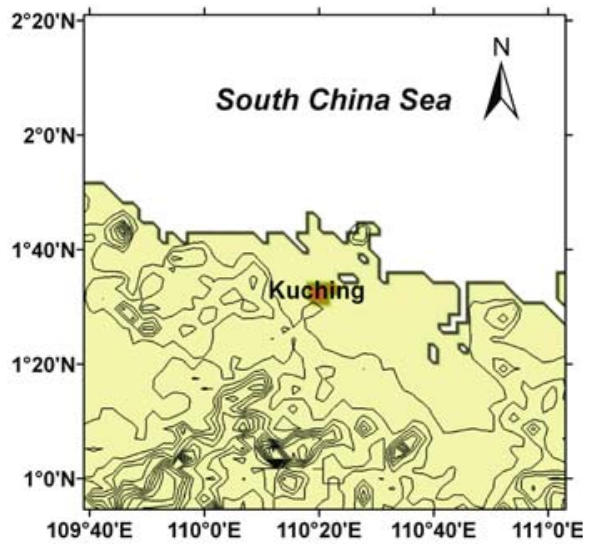

Figure 4. The domain of the nested grids for the simulation over Borneo at (a) $30 \mathrm{~km}$, (b) $10 \mathrm{~km}$ and (c) $3 \mathrm{~km}$ resolution.

than this size cannot be included in the analysis of the prognostic meteorological or pollutant modeling.

The meteorological component of TAPM utilizes the synoptic analyses from model output of LAPS (Limited Area Prediction) or the GASP (Global Analysis and Prediction) provided for by the Bureau of Meteorology, Australia (Luhar et al 1997). The boundary conditions for the outer grid of the model are obtained from the global scale of a horizontal resolution of $100 \mathrm{~km}$ at 6 -hour intervals. The output from either LAPS or GASP operational models assimilates meteorological observations from a network of global stations. Finer resolutions of the studied area can be selected, depending on the nested region that can model the required local scale.

Evaluation of the model was performed by utilizing simple statistics (Appendix). The root mean square error (RMSE) basically evaluates the variation between the model and observed values, and is a measure of the size of the error produced by the model. Low RMSEs indicate that the errors generated by the model are small and close to observed values. Other statistical parameters that can evaluate the errors of simulation are the systematic RMSE (RMSE ${ }_{S}$ ) and the unsystematic (random) RMSE $\left(\mathrm{RMSE}_{\mathrm{U}}\right)$. RMSE $\mathrm{S}_{\mathrm{S}}$ evaluates the variation of the fitted linear regression between the predicted and observed values, whereas the $\mathrm{RMSE}_{\mathrm{U}}$ calculates the difference between the fitted linear regression and the predicted values. The RMSE $E_{S}$ and $\mathrm{RMSE}_{\mathrm{U}}$ should be as small as possible for a "perfect' model. The RMSE $E_{S}$ assesses the model errors that are predictable, while the $\mathrm{RMSE}_{\mathrm{U}}$ assesses the random errors (Luhar et al 2004).

TAPM was run for a period of eleven days from the 17 to 27 of September to include the wind field conditions a few days prior to the height of the haze episode on 23 September. Three nested domains of $50 \times 50$ horizontal grid points at 30,10, and $3 \mathrm{~km}$ were centered at Kuching $\left(1^{\circ} 34^{\prime} \mathrm{N}, 110^{\circ} 22^{\prime} \mathrm{E}\right)$, the capital of the state of Sarawak (figure 4). The topography becomes increasingly more detailed from the coarser grid-resolution of $30 \mathrm{~km}$ to that of the $3 \mathrm{~km}$. The first domain (figure 4a) includes the western half of Borneo and a part of the South China Sea, while the final nested domain of $3 \mathrm{~km}$ grid spacing mainly focuses on the topography surrounding Kuching (figure 4c). The figure shows that the lowest topography is recorded at $50 \mathrm{~m}$, which is followed by the $100 \mathrm{~m}$ contour and subsequently at $100 \mathrm{~m}$ intervals. Kuching is a coastal town which faces the South China Sea to its north, and is located within a valley that is surrounded mainly by elevated hills near to its west and southern regions. Kuching is an urban area with a population of half a million people located approximately $18 \mathrm{~km}$ from the northwestern coast of Borneo. Approximately $75 \mathrm{~km}$ to its southwest is the Nuit Mountains National Park in Kalimantan Barat that peaks at $1.7 \mathrm{~km}$. The lowest five of the 25 vertical levels were selected at 10, 25, 50, 100 and $150 \mathrm{~m}$.

Correlation coefficients that measure the relationship between modeled and observed values are also evaluated. Another parameter computed is the 
Index Of Agreement (IOA), which is a measure of the degree of conformity between the observed and modeled results. The IOA is sensitive to the variations between the two parameters tested as well as the variations between the observed mean values. An IOA of one signifies a good conformity between model and observed values, while a value of zero signifies total disagreement (Luhar et al 2004). Several skill indicators were also evaluated. Skill is the skill score that compares the standard deviation of the model to the observed. A value of one indicates a good skill in predicting the parameter concerned. Skill $\mathrm{R}$ is the ratio between the RMSE and the standard deviation. Values less than one indicate a high skill. Skill $\mathrm{E}_{\mathrm{E}}$ is the ratio between the $\mathrm{RMSE}_{\mathrm{U}}$ and the standard deviation of the observed values.

\section{Results}

The present work addresses the important haze evidence that occurred over Borneo during the September of 1997. This section presents the various results obtained from the simulations of this event using TAPM. The low level wind regime, within the inner-most grid of $3 \mathrm{~km}$, illustrates the dominance of the land and sea breeze circulations between the northwestern coast of Borneo and the South China Sea for the entire duration of the eleven days (figure 5). The situation from the 22 to 23 of September 1997 is described in detail as this period coincides with the peak of the haze episode. Strong southeasterly winds with speeds more than $5 \mathrm{~m} \mathrm{~s}^{-1}$ dominated the South China Sea, flowing away from the land at 0745 local standard time (LST) on Day 6, corresponding to the 22 of September (figure 5a). The inland winds were also from the same direction, associated with the land breeze conditions. However, the strength of the wind speeds over land was of lower magnitude, at less than $5 \mathrm{~m} \mathrm{~s}^{-1}$, in contrast to the stronger winds over the sea.

The land breeze, along with the southeasterlies, was still evident over Sarawak in the latter part of the morning at 1130 LST (figure 5b). Stronger easterly winds were found over the South China Sea, while the southeasterlies were still present to the east of Kuching (denoted by C). However, to the north and west of Kuching, the winds have backed as easterlies, and were flowing parallel along the coast.

Figure 5(c) shows the situation at $1400 \mathrm{LST}$, where the windfield over land were eastsoutheasterlies, in contrast to the easterlies that have backed to northerlies in the South China Sea, causing the two streamlines (northerlies and southeasterlies) to converge along the coast of Sarawak.
Two-and-a-half hours later, at 1630 LST, strong sea breeze from the northeasterly direction flowed shoreward and infiltrated approximately $30 \mathrm{~km}$ inland. Due to the frictional considerations, the northeasterlies veered in a southwestward direction to the west of Kuching (figure 5d).

The sea breeze conditions were still dominant a few hours after sunset, at 2015 LST, with strong wind speeds of more than $5 \mathrm{~m} \mathrm{~s}^{-1}$ over the South China Sea (figure 5e). However, over Sarawak, the northeasterlies have weakened to less than $5 \mathrm{~m} \mathrm{~s}^{-1}$ with the setting of the land breeze phenomenon. The situation was maintained four hours later at midnight, but the winds from the South China Sea and over land have weakened considerably. By this time, the wind directions over land have reversed to very weak southwesterlies in the same places (figure 5f).

Trajectories from two sources were selected at a location near Pisang, in Kalimantan Tengah $\left(1^{\circ} 21^{\prime} \mathrm{N}, 109^{\circ} 50^{\prime} \mathrm{E}\right.$, noted as point $\left.\mathrm{A}\right)$ and the other, near Kampung Tanah Matang $\left(1^{\circ} 1^{\prime} \mathrm{N}, 110^{\circ} 44^{\prime} \mathrm{E}\right.$, noted as point $\mathrm{B}$ ), as representatives of air particles that originated from inland northwest Borneo. The air particles were released at midnight on Day 2, which corresponded to 18 of September 1997, and their trajectories were traced. Figure 5(a) shows the paths travelled by the particles from points A and B, approximately 128 hours after their release, corresponding to the 22 of September, a day prior to the highest MAPI recorded in Kuching.

The winds were generally from the southeast direction at $0745 \mathrm{LST}$, with wind speeds that were stronger over the South China Sea than over land. The aged particles, previously released up to 70 hours from point A charted a northward track towards the South China Sea, while the latter particles that were released 30 hours later were routed in a northwestward direction over land. The same situation also occurred for the air particles from point B, where over land, the aged particles followed a more northwestward direction, influenced by the southeasterlies (figure 5a).

The situation four hours later at $1130 \mathrm{LST}$ showed that the air particles from locations $\mathrm{A}$ and B followed a more northwestward direction over Sarawak and South China Sea, influenced by the strong southeastward winds over land and the eastward winds over sea (figure 5b). By 1400 LST, convergence of the seaward and landward winds along the coast of Borneo caused the air particles from points A and B (released 70 hours previously) to track westwards, influenced by the strong winds from the sea (figure $5 \mathrm{c}$ ).

Figure 5(d) shows that the strong landward winds from the sea enforced the air particles from points A and B to remain inland. Thus, if the air 
(a) 22 September, 0745 LST

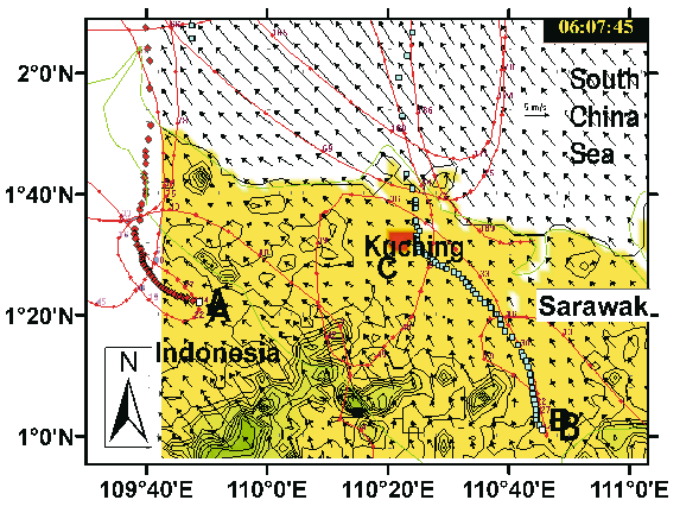

(c) 22 September, 1400 LST

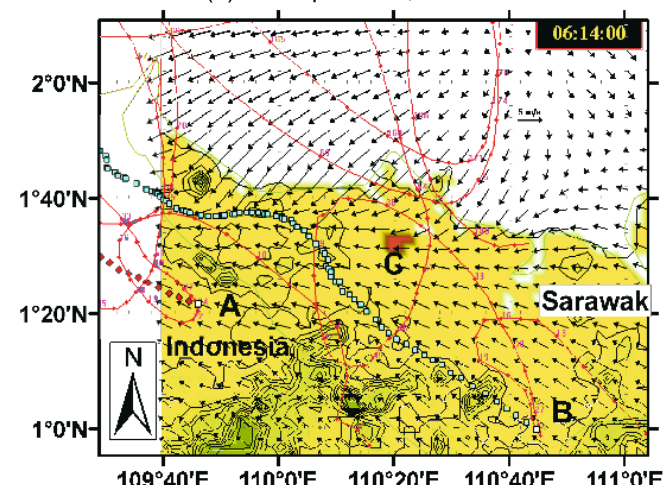

(e) 22 September, 2015 LST

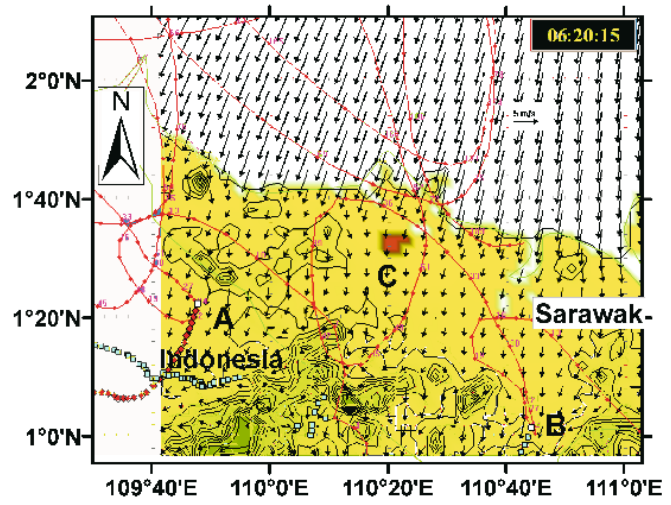

(g) 23 September, 0345 LST

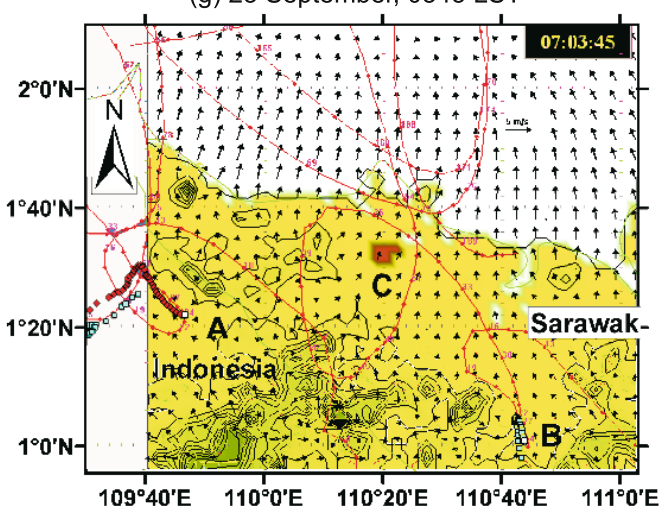

(b) 22 September, 1130 LST

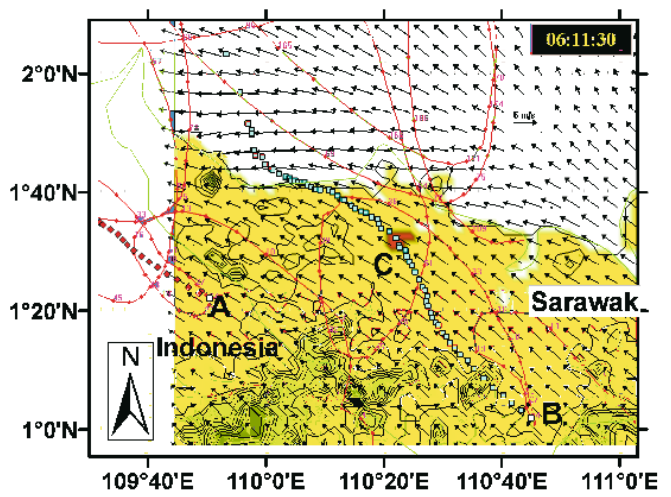

(d) 22 September, 1630 LST

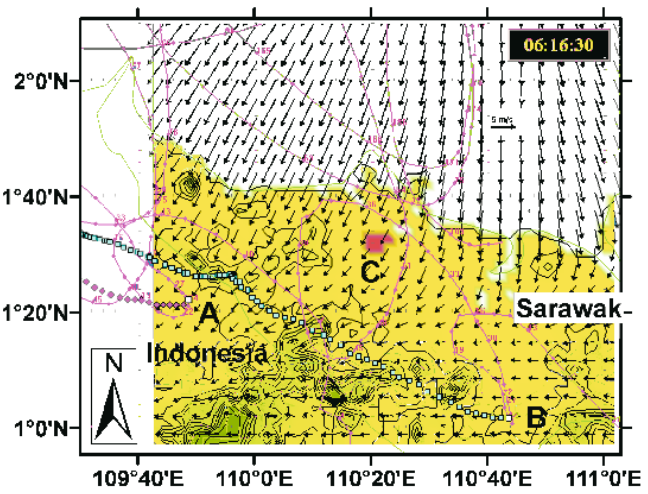

(f) 23 September, 0000 LST

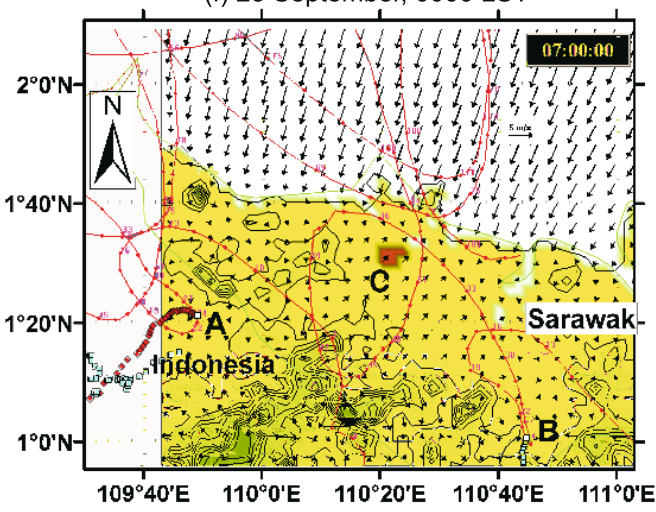

(h) 23 September, 0730 LST

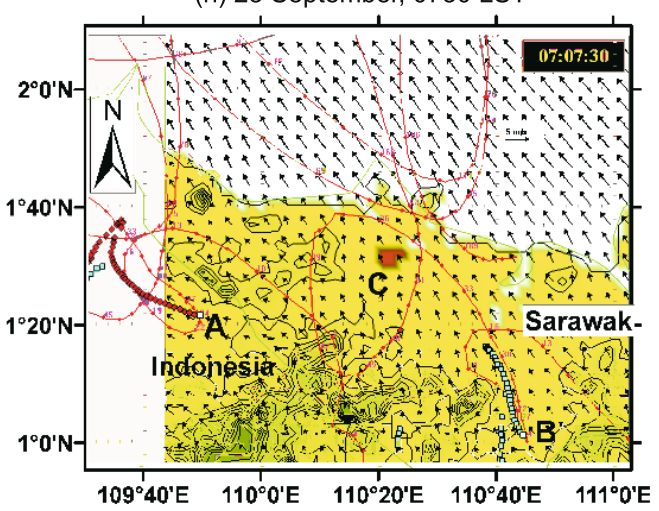

Figure 5. The selected hourly simulated wind regime on Day 6 and Day 7 which coincided with the 22 and 23 of September, respectively, in the area studied which included part of the South China Sea and Sarawak. The notation 06:11:30 corresponds to the simulation time on Day 6 at 1130 LST. The letters A and B represent points located at $109^{\circ} 46^{\prime} \mathrm{E}, 1^{\circ} 22^{\prime} \mathrm{N}$ and $110^{\circ} 44^{\prime} \mathrm{E}, 1^{\circ} 1^{\prime} \mathrm{N}$ 
Table 1. The statistical results for three meteorological parameters.

\begin{tabular}{|c|c|c|c|}
\hline Statistical parameters & $\begin{array}{l}\text { Wind speed } \\
\left(\mathrm{m} \mathrm{s}^{-1}\right)\end{array}$ & $\begin{array}{l}\text { Wind direction } \\
\text { (degree) }\end{array}$ & $\begin{array}{c}\text { Temperature } \\
\left({ }^{\circ} \mathrm{C}\right)\end{array}$ \\
\hline Observed mean & 1.22 & 171.89 & 25.82 \\
\hline Predicted mean & 2.32 & 179.65 & 28.11 \\
\hline $\begin{array}{l}\text { Standard deviation of } \\
\text { prediction }\end{array}$ & 0.58 & 77.42 & 4.43 \\
\hline $\begin{array}{l}\text { Standard deviation of } \\
\text { observed }\end{array}$ & 0.85 & 86.47 & 2.37 \\
\hline Variance of observed & 1.22 & 5993.9 & 5.63 \\
\hline Variance of predicted & 2.32 & 7476.6 & 19.58 \\
\hline Correlation & 0.45 & 0.57 & 0.79 \\
\hline $\begin{array}{l}\text { Maximum deviation } \\
\text { from observed mean }\end{array}$ & 2.02 & 187.11 & 6.28 \\
\hline $\begin{array}{l}\text { Minimum deviation } \\
\text { from observed mean }\end{array}$ & -0.86 & -168.89 & -1.22 \\
\hline $\begin{array}{l}\text { Maximum deviation } \\
\text { from predicted mean }\end{array}$ & 2.58 & 178.35 & 8.59 \\
\hline $\begin{array}{l}\text { Minimum deviation } \\
\text { from predicted mean }\end{array}$ & -1.12 & -174.65 & -5.41 \\
\hline $\begin{array}{l}t \text {-test between observed } \\
\text { and predicted values }\end{array}$ & -25.35 & -1.19 & -12.94 \\
\hline $\begin{array}{l}\text { Index Of Agreement } \\
\text { (IOA) }\end{array}$ & 0.45 & 0.57 & 0.79 \\
\hline RMSE & 1.30 & 105.81 & 3.68 \\
\hline Bias-systematic RMSE & -1.10 & -7.75 & 2.30 \\
\hline Systematic RMSE & 1.10 & 62.98 & 2.58 \\
\hline Unsystematic RMSE & 0.69 & 85.03 & 2.62 \\
\hline Skilly $_{V}$ & 1.48 & 1.12 & 1.86 \\
\hline Skill $_{\mathrm{R}}$ & 2.25 & 1.37 & 1.55 \\
\hline Skill $_{\mathrm{E}}$ & 1.20 & 1.10 & 1.10 \\
\hline
\end{tabular}

parcels from points $\mathrm{A}$ and $\mathrm{B}$ were already polluted with smoke, then they would be impeded from dispersing over the sea, causing the inland air pollution levels to increase. Figure 5(e and f) displayed similar situations of the wind regime at 8 pm (2000 LST) and midnight, respectively, where the strong landward winds forced the air particles from points A and B to remain over land for more than 12 hours since 1400 LST.

It can be generalized that the results of the simulation showed that during the peak of the haze episode, the trajectories of air particles from two inland locations in northwest Borneo remained over land for most of the time due to the shoreward winds from South China Sea during daytime. This prevented any polluted air particles from being transported offshore. Recirculation of the land and sea breeze phenomena impeded efficient transportation and dispersion of smoke at low levels.

The hourly observed meteorological data at the Kuching station was compared with the simulated data. Generally, the simulated wind speeds were always overestimated, where the magnitudes of wind speeds were higher than the observed values, with a correlation of 0.45 (table 1 ). The time series showed that the simulated daily maximum wind speeds of more than $3.5 \mathrm{~m} \mathrm{~s}^{-1}$ were attained by mid-day, with the highest wind speed generated at 1500 LST on the 21 of September (figure 6a). Generally, the observed wind speeds were low, of magnitudes $2 \mathrm{~m} \mathrm{~s}^{-1}$ during the period of investigation, with a mean wind speed of $1.22 \mathrm{~m} \mathrm{~s}^{-1}$, and a maximum deviation of $2.2 \mathrm{~m} \mathrm{~s}^{-1}$ from the observed mean in contrast to a maximum deviation of $2.58 \mathrm{~m} \mathrm{~s}^{-1}$ for the simulated mean wind speed (table 1). Maximum wind speeds were attained during daytime (usually by mid-day), whereas the minimum average wind speeds of $0.5 \mathrm{~m} \mathrm{~s}^{-1}$ usually occur during night-time. The simulated mean wind speed was approximately double that of the observed mean wind speed (table 1). The sinusoidal patterns of the wind speeds displayed the waxing and waning features of the land and sea breeze conditions that occur during night-time and daytime, respectively.

The diurnal patterns between the simulated and observed wind directions were at times out of phase (figure 6b), particularly on the 21 September, and from the 23 to 25 of September, which was 

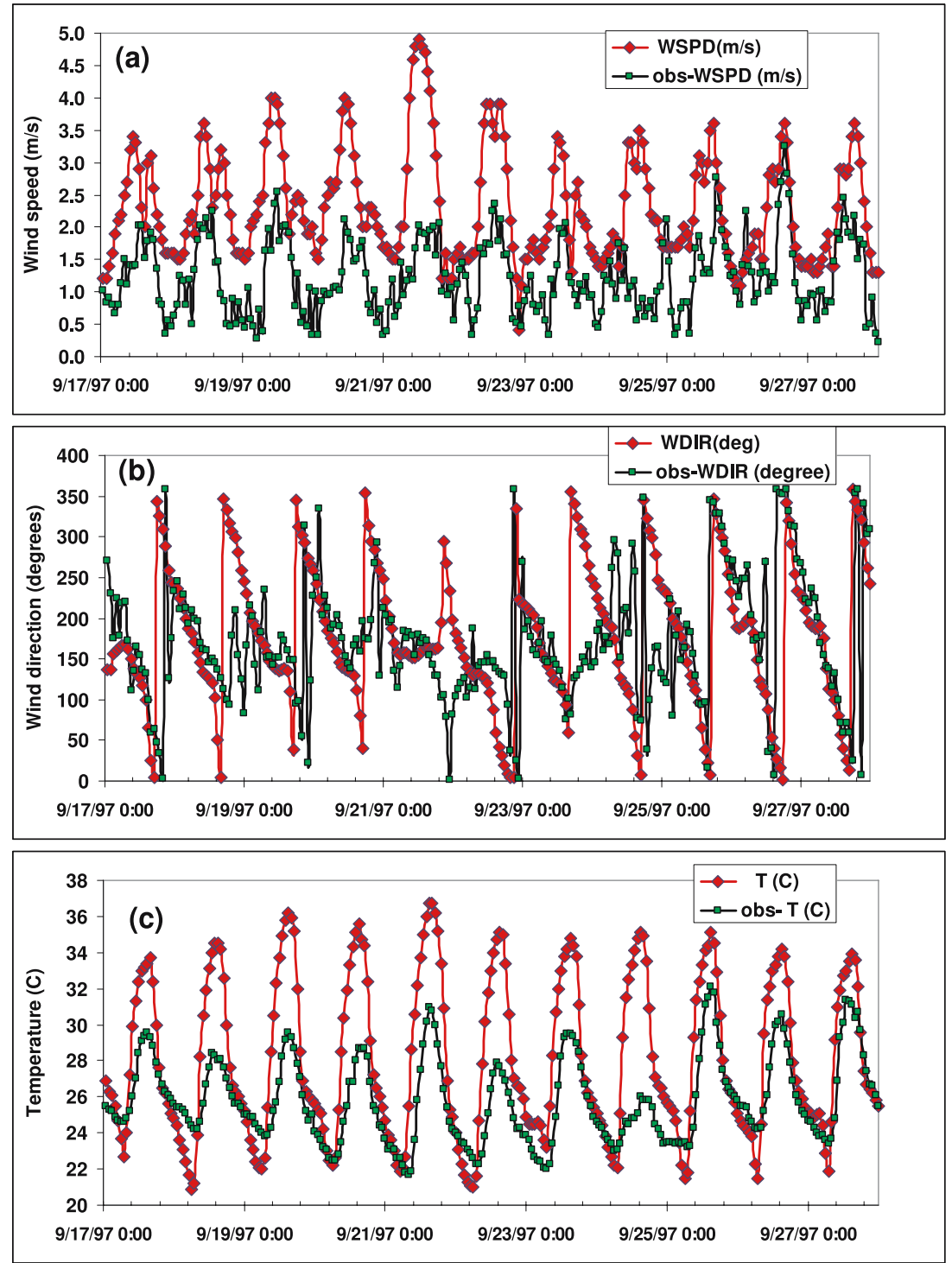

Figure 6. Time series of the assimilated meteorological parameters by TAPM and the observed parameters of (a) wind speed, (b) wind direction, and (c) temperature, at Kuching from the 17 to 27 of September 1997.

coincident with the height of the haze episode. Of particular interest is the maximum simulated wind speed at mid-day that was out of phase with the minimum observed wind speed on the 23 of September. The simulated winds backed from the northeasterlies to northwesterlies at $1600 \mathrm{LST}$. The maximum deviation from the mean observed wind direction was $187^{\circ}$ on the 26 of September at $1500 \mathrm{LST}$, in contrast to the maximum deviation of $178^{\circ}$ from the simulated mean that occurred on the 27 of September at 1700 LST. On the contrary, the minimum deviation from the observed mean of $-169^{\circ}$ occurred on the 21 of September at $1500 \mathrm{LST}$, compared to the deviation of $-187^{\circ}$ that occurred on the 26 September at 1700 LST for the simulated wind direction. The mean observed wind directions were mainly from the south-southeast, in contrast to the southerly winds predicted by the model (table 1). The observed wind directions followed a repeated cycle, where the winds were from the northerly directions from mid-day, which then backed throughout the afternoon as southwesterlies, and became easterlies by midnight. They then slowly veered as southwesterlies towards mid-day.

The diurnal patterns of the simulated and observed temperatures were similar, where minimum temperatures occurred at approximately 3-4 am in the morning, and maximum temperatures were generally attained by mid-day. However, the simulated temperatures were higher than the observed temperatures by a range of $4^{\circ}-6^{\circ} \mathrm{C}$. The mean simulated temperature was $28.1^{\circ} \mathrm{C}$ compared to the mean observed of $25.8^{\circ} \mathrm{C}$. The standard deviation of observed temperature was $2.4^{\circ} \mathrm{C}$ compared to the standard deviation of $4.4^{\circ} \mathrm{C}$ for the 

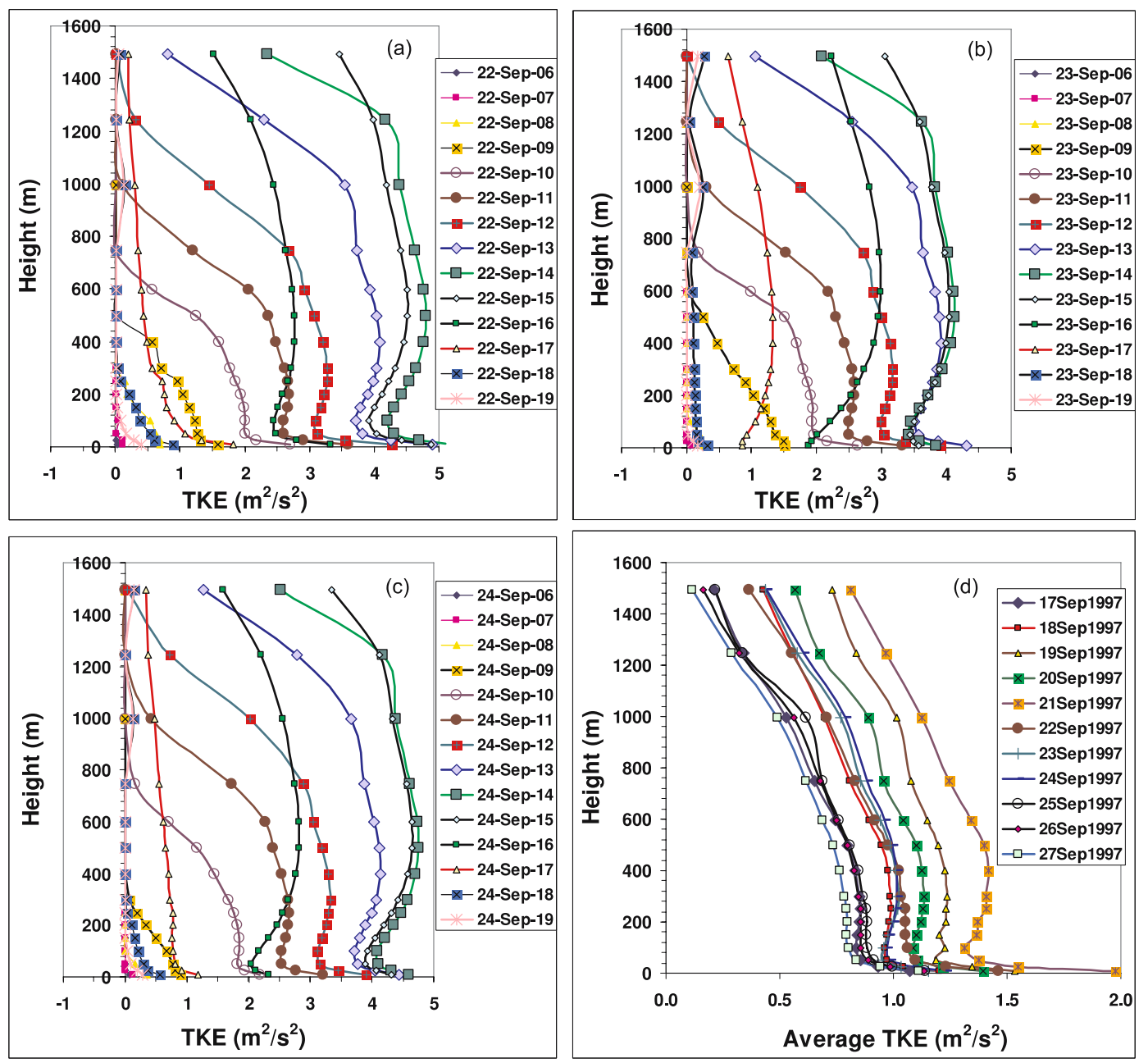

Figure 7. Turbulent kinetic energy (TKE) profiles on (a) 22 September, (b) 23 September, (c) 24 September, and (d) daily averaged TKE profiles from the 17 to 27 of September 1997.

simulated temperature. The maximum deviation of observed temperature from the mean was $6.3^{\circ} \mathrm{C}$ in contrast to the deviation of $8.6^{\circ} \mathrm{C}$ for the simulated temperature. The minimum deviation from the mean of the simulated temperature was $5.4^{\circ} \mathrm{C}$ compared to that of only $1.2^{\circ} \mathrm{C}$ for the observed temperature. This implies a high variability in the daily simulated temperatures, particularly on the 21 and the 19 of September. The surface cooling is reflected in the lower observed maximum daily temperatures that ranged from $26^{\circ} \mathrm{C}$ to $28^{\circ} \mathrm{C}$ from the 18 until the 25 September, coincident with the height of the haze episode, where the aerosols present in the haze prevented solar radiation from reaching the surface of the earth at Kuching.

The differences between the simulated and observed parameters were determined by the $t$-test. The negative calculated $t$ values for all the parameters indicated that the mean of the observed parameters were lower than the simulated values for all the parameters investigated (wind speed, wind direction and temperature).
The results showed that the wind speeds and temperatures displayed significant differences between the observed and the mean values at the alpha value of 0.5 .

The RMSEs of all the meteorological parameters were generally lower than the predicted standard deviations. Ideally, a skillful model is represented by the RMSE values that are smaller than standard deviations. The $\mathrm{RMSE}_{\mathrm{S}}$ was also relatively higher than the RMSE, whereas the $\mathrm{RMSE}_{\mathrm{U}}$ was generally smaller than either the $\mathrm{RMSE}_{\mathrm{S}}$ or RMSE, except for the wind directions. Although the requirement for a good and skillful model is that the $\mathrm{RMSE}_{\mathrm{U}}$ should be larger than the systematic RMSE, the results showed otherwise. The magnitudes of the RMSE from this study were comparatively larger than the RMSEs obtained for the Kincaid or Indianapolis values found by Luhar and Hurley (2003). Most of the wind component and temperature parameters in the US sites were generally less than one, in contrast to the values generated here. 
Moderately high IOAs were displayed by all the parameters, except temperature which displayed a high IOA of 0.79 . This is in contrast to the higher IOA values of more than 0.89 from the results at the American sites at Kincaid and Indianapolis that represent a mid-latitude environment (Luhar and Hurley 2003). The skill $\mathrm{V}$ values showed that the model was slightly overpredicting all parameters (table 1). The skill $\mathrm{E}_{\mathrm{E}}$ parameter showed that errors not simulated mathematically by model were higher for wind speed than the wind direction and temperature.

Turbulent kinetic energy (TKE), a measure of the intensity of turbulence in the planetary layer, is also investigated to understand the dispersion characteristics during the height of the haze episode. The simulation of TKE over the eleven-day period showed a dramatic increase and decrease of TKE throughout the day (figure 7). TKE tends to increase in magnitude with height from early morning and reached a maximum from mid-day to early afternoon and gradually decreased towards sunset. This represents the generation and decay cycle of the TKE in the air. The depths of the TKE profile also varied with time, where throughout the night, TKE was generally zero, but increased gradually from a depth of approximately $100 \mathrm{~m}$ after sunrise to a height of about $1.4 \mathrm{~km}$ during the day, before decreasing to depths of less than $500 \mathrm{~m}$ by sunset.

The hourly TKE profiles on individual days from the 22 to 24 of September showed that the daily maximum profiles occurred at approximately 1400 LST, with the magnitudes of profiles larger on the 22 and 24 but reduced on the 23 September (figure $7 \mathrm{a}$ to $\mathrm{c}$ ). The TKE profiles were slightly higher with a maximum of nearly $5 \mathrm{~m}^{2} \mathrm{~s}^{-2}$ on the 22 and 24 of September, one day prior and after the peak of the haze, in contrast to the TKE profile on the 23 of September (figure 7b). The daily average vertical TKE profiles shown in figure 7 (d) illustrate variability within the profiles, where the maximum TKE profile of $1.4 \mathrm{~m}^{2} \mathrm{~s}^{-2}$ was attained below the height of $400 \mathrm{~m}$ on the 21 September. The magnitudes of the profiles decreased thereafter from the 23 to 27 of September.

The above situation illustrates the formation of a strong stable layer near the surface of the earth due to the radiative cooling of the ground, where turbulence is less diffusive (Moraes et al 2005). The wind speed then gradually increased from mid-morning, and reached a peak at approximately $3 \mathrm{pm}$ with an average value of $3.5 \mathrm{~m} \mathrm{~s}^{-1}$, before it decreased thereafter.

It can be inferred from this study, that the local wind conditions were not conducive in efficient transportation of air particles towards the sea at low levels due to the presence of the recurring weak land breeze during night-time. Turbulence is generally suppressed during night-time by buoyancy forces where the cooling of the earth induces a negative heat flux that is directed to the surface of the earth (Stull 1998), as shown by the near-zero vertical profiles of the TKE during night-time.

\section{Conclusion}

The statistical evaluation had shown that the TAPM model was moderately skillful at predicting the meteorological parameters, with moderately high correlations between the predicted meteorological parameters such as temperature and wind speed compared to the observed values. The presence of the land and sea breeze circulations limited the efficient transportation and dispersion of pollutants from inland Kalimantan. Trajectory analysis showed that the aged polluted air particles from inland Borneo were advected landwards and seawards. Further, southward movement of air particles were blocked to a certain extent by the Nuit Mountains National Park in Kalimantan Barat. Weak TKE within the lowest kilometer of the planetary boundary layer were associated with low turbulence and increased pollution during the height of the haze period. During nighttime, the low hourly TKE profiles were associated with the weak wind speeds of the land breeze circulation.

This paper did not investigate the dispersion characteristics of the model due to the area of investigation that was bounded by the $3 \mathrm{~km}$ grid. Moreover, the emission sources did not fall within the grid area nor were the daily sources of fires available, which limit the inclusion of all the transboundary emitted sources. Further studies will include use of a much higher model resolution and trying of several model parameters for equatorial applications. The $1 \mathrm{~km}$ or lower grid-resolution utilizing this model would be limited to a small study area centered in the middle of Kuching, and not include a part of the South China Sea region. Nevertheless, this preliminary study has established the effect of the land and sea breeze features of a coastal town, and provided a basis for a future study on the investigation of a high resolution model over a smaller area. The prediction of the low wind velocities is a problem encountered in this study, which resulted in the overprediction of the wind speeds and at times the wind directions. The problem arises with the night-time to early morning wind velocities, where the low heat flux under stable boundary conditions produces errors in the wind predictions, as explained by the originators of TAPM (Luhar et al 2007). Moreover, 
the presence of the thick blanket of aerosols over Sarawak and the anomaly of the equatorial zonal winds over the Pacific and Indian oceans during the strongest El Niño of the century (Gadgil et al 2007) also added to the impediment in predicting the low level winds, which produced larger errors than expected (Mahmud 2009). The errors produced by the model during the selected period are acceptable as shown by the statistical evaluation that illustrated the moderate skill of the model, through the IOA, which are also comparable in the magnitude of errors generated in other studies (Luhar and Hurley 2004, 2007).

Transportation and dispersion modelling in low wind conditions is important as in such conditions pollutants are not able to travel far and thus affect the areas near the source that may retain high concentrations. This study has shown that the low level wind regime at coastal locations which consists of the land and sea breeze circulation characteristics embedded within the southwest monsoon was unable to transport or disperse the extremely high loadings of pollutants associated with the uncontrolled large-scale burning in Borneo. A study on the temporal and spatial scales of dispersion of the polluted particles with a selection of high resolution model configuration deserve further investigation so that the properties and behaviour of the transportation and dispersion of polluted air particles could be predicted so that positive steps can be undertaken by the local and international authorities to manage and reduce the impacts of fires in the future.

\section{Appendix}

Systematic root mean square error,

$$
\mathrm{RMSE}_{\mathrm{S}}=\sqrt{\frac{1}{N} \sum_{i=1}^{N}\left(\hat{P}_{i}-O_{i}\right)^{2}}
$$

Unsystematic root mean square error,

$$
\mathrm{RMSE}_{\mathrm{U}}=\sqrt{\frac{1}{N} \sum_{i=1}^{N}\left(\hat{P}_{i}-P_{i}\right)^{2}}
$$

Index of agreement,

$$
\mathrm{IOA}=1-\frac{\sum_{i=1}^{N}\left(P_{i}-O_{i}\right)^{2}}{\sum_{i=1}^{N}\left(\left|P_{i}-O_{\text {mean }}\right|+\left|O_{i}-O_{\text {mean }}\right|\right)^{2}}
$$

Skill $_{\mathrm{V}}$,

$$
\text { Skill }_{\mathrm{V}}=\frac{P_{\mathrm{std}}}{O_{\mathrm{std}}}
$$

Skill $_{R}$,

$$
\text { Skill }_{\mathrm{R}}=\frac{\mathrm{RMSE}}{O_{\text {std }}}
$$

and Skill ${ }_{\mathrm{E}}$,

$$
\operatorname{Skill}_{\mathrm{E}}=\frac{\mathrm{RMSE}_{\mathrm{U}}}{O_{\mathrm{std}}}
$$

where $P$ represents the predicted value and $O$ represents the observed value.

(Source: Luhar et al 2004 and Hurley et al 2005).

\section{References}

Draxler R R and Hess G D 1998 An overview of the HYSPLIT4 modeling system for trajectories, dispersion and deposition; Austr. Meteorol. Mag. 47 295-308.

Draxler R R, Stunder B, Rolph G and Taylor A 2008 HYSPLIT4 user's guide; NOAA Technical Memorandum, Revised February 2008.

Gadgil S, Rajeevan M and Francis P A 2007 Monsoon variability: Links to major oscillations over the equatorial Pacific and Indian oceans; Curr. Sci. 88(12) 182-194.

Halland J J, Fuelberg $\mathrm{H}$ E, Pickering $\mathrm{K}$ E and Luo M 2008 Identifying convective transport of carbon monoxide by comparing remotely sensed observations from TES with cloud modeling simulations; Atmosphere Chemistry Physics Discussion 8(6) 19,201-19,247.

Hurley P J 1997 An evaluation of several turbulence schemes for the prediction of mean and turbulent fields in complex terrain; Bound.-Layer Meteor. 83 43-73.

Hurley P J and Luhar A K 2000 The Kwinana coastal fumigation study: Meteorological and turbulence modeling on selected days; Bound.-Layer Meteor. 94 115-138.

Hurley P J, Blockley A and Rayner K 2001 Verification of a prognostic meteorological and air pollution model for year long predictions in the Kwinana region of Western Australia; Atmos. Environ. 35 1871-1880.

Hurley P, Manins P, Lee S, Boyle R, Ng Y L and Dewundege P 2003 Year-long, high resolution, urban airshed modeling: Verification of TAPM predictions of smog and particles in Melbourne, Australia; Atmos. Environ. 37 1899-1910.

Hurley P J, Physick W L and Luhar A K 2005 TAPM: A practical approach to prognostic meteorological and air pollution modeling; Environmental Modelling \&5 Software $20737-752$.

Katzfey J J and Ryan B F 1997 Modification of the thermodynamic structure of the lower troposphere by the evaporation of precipitation: A GEWEX cloud system study; Mon. Weather Rev. 125 1431-1446.

Kaufman J Y, Koren I, Remer L A, Rosenfeld D and Rudich Y 2005 The effect of smoke, dust, and pollution aerosol on shallow cloud development over the Atlantic Ocean; Proc. Natl. Acad. Sci. 102(32) 11,207-11,212. 
Koe L C C, Arellano Jr A F and McGregor J L 2001 Investigating the haze transport from 1997 biomass burning in Southeast Asia: Its impact upon Singapore; Atmos. Environ. 35 2723-2734.

Kowalczyk E A, Garratt J R and Krummel P B 1991 A soil-canopy scheme for use in a numerical model of the atmosphere 1D Stand Alone Model; CSIRO Atmospheric Research Technical Paper No. 23, 56 pp.

Levine J S 1994 Biomass burning and the production of greenhouse gases, in the climate biosphere interaction; In: Biogenic Emissions and Environmental Effects of Climate Change; (ed.) Zepp Z G, John Wiley \& Sons, Inc.

Luhar A, Galbally I, Hibberd M and Bently S 1997 Final Report on Meteorological and Dispersion Modeling using TAPM for Wagerup, Phase 2: Dispersion; CSIRO Report C/0986, pp 62.

Luhar A, Galbally I and Hurley P J 2004 Final Report on Meteorological and Dispersion Modeling using TAPM for Wagerup. Phase 1: Meteorology; CSIRO Report C/0810, pp 80.

Luhar A K and Hurley P J 2003 Evaluation of TAPM, a prognostic meteorological and air pollution model, using urban and rural point-source data; Atmos. Environ. 37 $2795-2810$.

Luhar A K, Hurley P J and Rayner K N 2007 Modelling low wind-speed stable conditions in a prognostic meteorological model and comparison with field data;
Proceedings of the 11th International Conference on Harmonisation within Atmospheric Dispersion Modelling for Regulatory Purposes held in Cambridge, U.K. July 2007, 251-255.

Mahmud M 2009 Simulation of equatorial wind field patterns with TAPM during the 1997 haze episode in Peninsular Malaysia; Accepted by the Singapore Journal of Tropical Geography.

Moraes O L L, Acevedo O C, Degrazia G A, Anfossi D, da Silva R and Anabor V 2005 Surface layer turbulence parameters over a complex terrain; Atmos. Environ. 39(17) 3103-3112.

Oke T R 1988 The urban energy balance; Prog. Phys. Geog. $12471-508$.

Pielke R A 1984 Mesoscale Meteorological Modelling (Odando: Academic Press) pp. 612.

Qadri T S (ed.) 2001 Fire, smoke, and haze; The ASEAN response strategy, Philippines, Asian Development Bank, pp 246.

Rowell A and Moore P 2000 WWF/IUCN Global Review of Forest Fires (Gland, Switzerland) pp. 64.

Siniarovinaa U and Engardtb M 2005 High-resolution model simulations of anthropogenic sulphate and sulphur dioxide in Southeast Asia; Atmos. Environ. 39 2021-2034.

Stull R B 1988 Introduction to Boundary Layer Meteorology (Dordrecht: Kluwer Academic Publishers), pp. 666. 